\title{
EDITORIAL
}

\section{Development of Sports and Exercise Medicine in Sri Lanka - The role of SLSMA}

\author{
Chelliah Thurairaja ${ }^{1}$
}

This article contains updated extracts of the article, 'SPORTS M EDIEN CE' which was published in 'H istory of M edicinein Sri Lanka' by Sri Lanka M edical A ssociation (SLM A).

“Organized physical activity for persons of all ages, performance enhancement of elite athletes, physical activity and exercise for health, recreational sports, and all aspects of formal exercisetraining need to follow the principles advocated in thescienceand technology of sports and exercisemedicine to achieve enhancement in performance and obtain the benefits of exercisefor health."

Sports Medicine is the branch of medicine that deals with physical fitness, treatment and prevention of injuries related to sports and exercise. Although mostsports teams haveemployed "Team physicians" for many years, it is in very recent few years that Sport and ExerciseM Medicinehasemerged as a district entity in health care.

\section{Historical background of organizational Sports Medicine- Globally}

1. Sports Medicine, as a separatemedical discipline was identified globally in 1928. It came under the purview of the International Federation of Sports Medicine, FIMS which is Federation Internationale de Medecine du Sports, formed shortly following thefirst of the modern Olympic Games. FIMS today is the only recognized international body for Sports M edicine.

2. It is a structured and well-organized association, strongly committed to the promotion of thestudy and development of sports medicinethroughout the world. The purpose and administration of FIMSisclearly set out in its Statutesand By-Laws. FIMS is made up of Continental and National sports medicine associations, as well as multinational groups and individual members.

\footnotetext{
${ }^{1}$ Founder President of Sri Lanka Sports Medicine Association (SLSMA).

Correspondence: CT, e-mail: <dr.thurai@gmail.com>
}

3. FIMS is a recognized federation of the International Olympic Committee(IOC) and of WADA - theWorld A nti-Doping Agency and an affiliate of the United N ations Educational, Scientific and Cultural Organization (UNESCO).

4. As FIMS was born under the umbrella of the Olympic Games, the strong association with the International Olympic Committee (IOC) is illustrated and reflected in thefive Olympic rings in theFIMS flag and logo. FIMS continuesto grow as an international community of sports medicine specialists, researching and practicing thelatest techniques in medicine for athletes and others who lead activelives.

5. FIMS is constituted by the amalgamation of the Continental or Regional Federations of which the Asian Federation of Sports Medicine/ AFSM (an affiliation of 46Asian countries) is recognized as the largest Regional Federation in terms of members, of member countries.

6. The Sri Lanka Spots Medicine Association (SLSMA), was first recognized as the National Association of Sri Lanka, by AFSM, which was the first requirement for its acceptance (or eligibility) for recommendation and membership to the FIMS fraternity. SLSM A that wasinitially formed in 1990 was affiliated to AFSM in 1992 and accepted as a member of FIMS in 1994.

7. In addition to its activerolein FIMS, SLSMA took greater strides in theA sian Federation of Sports Medicine (AFMS) that overlook the promotion and administrations of sports medicine in the 46 countries in Asia. The president SLSMA at that timeDr. C Thurairaja, was elected to the A FSM executivecommittee, who thereafter becamethe longest serving Vice President and was later, inducted as President of AFSM from 2010 to 2012.

\section{Historical background and beginning of Sports Medicine in Sri Lanka}

1. The history of Sports Medicine in Sri Lanka began in the late 1980s, initiated under the guidance of a core group of senior members consisting of Professor Rohan Jayasekara and 
Dr. Lalith Wijeyaratne, Dr. B.J.C. Perera, Dr. Hilarian Cooray, Dr. C. Thurairaja and Orthopedic Surgeons, Dr. N arendra Pinto and Dr. H.J. Suraweera. Mentioning is necessary of the pioneering work, commitment and guidance of late Dr. P.A.P. Joseph, Surgeon Kandy G.H., Dr. Mrs. Shreen Wilathgamuwa (Treasurer), Dr. HemanthaWickramathilake(Secretary General), Dr. Nimal Herat Gunaratne (who followed as theSecretary General) and Mr. Francis A Imeida who coordinated all meetings at his residence.

2. The Sri Lanka Sports Medicine A ssociation (SLSMA) pioneered Sports Medicine in Sri Lanka. Sports Medicine was first identified in Sri Lanka as a separate discipline in the mid1980s dueto a group of dedicated doctors who led the way to SLSMA being officially formed in 1990. SLSMA was recognized as the national organization by the Ministry of Sports and then affiliated to the AFSM in 1992. Affiliation of SLSMA to FIMS followed in 1994. A FSM endorsed SLSMA as a national association in the Asian Region. It was only then, that SLSMA was recognized by FIMS as the national sports medicine association of Sri Lanka.

3. The Founder President of SLSMA, Dr. C. Thurairaja, was nominated to the Education Commission of FIMS in 1998 and continued in that position from 1994 to 2002. Hewas elected to the FIMS executive committee to serve as ExCo member from 2002 to 2010.

4. In June 1998, a milestone was achieved for Sri Lanka when the coursecontents and syllabus of the FIMS Team Physician Course to be held in Sri Lanka and its proposed local SLSMA Faculty, was approved at the XXVIth World Sports MedicineCongress in Orlando, Florida, USA. Sri Lanka was selected to conduct the $1^{\text {st }}$ FIMS Team Physician Course in Asia.

5. This became the first FIMS Team Physician Coursefor doctors to beheld in Sri Lanka in 1998. It was conducted by the teaching faculty that induded fiveFIMS recognized doctors of SLSMA, along with members of the international FIMS teaching faulty.

6. This was followed by thenomination of Colombo to host the first AFSM World Congress in 2003, along with the FIMS Team Physician course in commemoration of the $75^{\text {th }}$ A nniversary of FIMS. Consequently, Colombo was listed as one of seven Global Education Centers in Sports Medicineof FIMS.
7. SLSMA expanded its international involvement when another founder ExCo member Dr. Lalith Wijeyaratne was elected to the executivecommittee of AFSM. Professor Vajira Dissanayake, Dr. Asela Rathnayake were also selected to serve in the Education Commission of AFSM and Dr. A ranjan Karunanayake in the Anti-Doping Commission. Thelatter two doctors werePost Graduatelnstitute of Medicine(PGIM) University of Colombo trainees who obtained the PGIM Diploma in Sports M edicine- Sri Lanka.

8. SLSMA sinceits inception in 1992 was the sole body committed to the promotion of Sports Medicine in Sri Lanka. It organized and conducted Sports M edicine seminars for doctors and medical students, awareness programmes on "Exercise for Health" to the corporate and public sectors, seminars on the "Principles of Sports Medicine" for coaches, trainers and athletes, on an annual basis. This was in addition to theFIMS accredited Team Physicians Courses for doctors.

9. The next progression academically was the formation of the Board of Study in Sports Medicine (BOSSM) of PGIM in 2006. The Sri Lankan FIMS faculty of 1998 and 2003, namely Professor Rohan Jayasekara, Dr. Lalith Wijeyatane, Dr. B.J.C. Perera, Dr. Hilarian Cooray, Dr. C. Thurairaja and Orthopedic Surgeons, Dr. Narendra Pinto and Dr. H.J. Suraweera formed theinaugural Board of Study.

10. This Board formulated the curriculum and contents of the Post GraduateCourseof study, to award the Diploma in Sports Medicine for doctors. The PGIM approved the Diploma in Sports Medicine as a part of the postgraduate teaching programme.

11. TheSports M edicinecurriculum for thefirst postgraduate certified course in Sri Lanka, the Diploma in Sport Medicine conformed both to international requirements of Sports M edicine and the academic requirements of PGIM. The need to conform to international requirements of Sports Medicine teaching standards was to ensurethat ultimately the qualified doctors who accompanied teams abroad and provided medical care to our sportsmen and sportswomen, had the required capability and necessary expertise considered as basic qualifications in Sports Medicine, that are recognized globally.

12. During the same period, Sports Medicine was included as a subject in the undergraduate 
curriculum within the musculoskeletal module at the Faculty of Medicine, Colombo. This was due to the foresight of Professor Rohan Jayasekara, the inaugural chairman, Board of Study in Sports Medicine and Head of A natomy and Genetics, Faculty of Medicine who subsequently became the Dean, Faculty of Medicine, University of Colombo.

13. Sports Medicine Services to athletes and members of the public were initiated in the Health sector at the NHSL by Dr. Lalith Wijeratne, at the Rheumatology Clinic with the assistance of other sports medicine doctors who participated on a voluntary basis. The Physiotherapy Department, NHSL under the administration of Dr. Lalith Wijerathne, was the location for the required physiotherapy and rehabilitation of muscul oskeletal injuries based on sports medicine principles to be carried out. This further served to highlight the role and importance of the liaison of sports doctors and physiotherapists.

14. From 2012-2018 another significant event happened in the history of Sports Medicine in Sri Lanka. That is the development of the curriculum of MD in Sport and Exercise M edicine course of the Post Graduate Institute of Medicine (PGIM), University of Colombo and starting the post graduate training of the first batch of registrars in Sports and Exercise Medicine. Final curriculum of theMD in Sports and ExerciseM edicineprogrammewas prepared after reviewing the Postgraduate Sport and Exercise Medicine curriculums of Faculty of Sport and Exercise Medicine, United Kingdom, University of Bath, United Kingdom and A ustralian College of Sports M edicine. Several Board of study members and foreign specialists in Sport and Exercise M edicine, were involved in designing the final curriculum. A significant amount of timeand efforthad to beput by Dr. C. Thurairaja, Professor Rohan Jayasekera, Dr. Lalith Wijerathne, Dr. H.J. Suraweera, Dr. B.J.C. Perera, Prof. Thashi Chang, Dr. Harindu Wijesinghe, Prof. Madawa Chandrathileke, Prof. Aranjan Karunanayake and Dr. Thamindu Wedathilaka to design and start the present MD in Sport and Exercise Medicine programme. Professor Janaka de Silva and Professor Jayantha Jayawardene gave their fullest encouragement and support to theboard of study members as the directors of the Post Graduate Institute of Medicine.

\section{Sri Lankan postgraduate Sports M edicine activities}

1. The Diploma in Sports M edicinewas started as the initial qualification in terms of COD, and the MD programmeto obtain the specialist status of a consultant. TheDiploma was identified, as the initial step towards providing the pre requisite knowledge to proceed to the MD, which is the qualification to be a consultant in Sports Medicine.

2. The aim of the BOSSM was to provide the country with the 'first level' of qualified, trained and Certified Diplomates in Sports M edicine At the moment there are over 70 doctors who have obtained the Diploma level qualification. This identified theneed to train and providethenext level of specialists in Sports Medicine, who would became board Certified Specialties in Sport Medicine with the postgraduate degree of MD, Sports Medicine.

3. The Specialist in Sports M edicineis expected to provide a specialist service to athletes and members of the public who need expert care, management, rehabilitation and advice on all requirements of exercise, fitness, sports, sports injuries, prevention of injuries and prevention of medical conditions known as Non Communicable Diseases (NCD), that results most often dueto lack of physical activity.

4. The Board of Study, PGIM started the training program for the MD in Sports and Exercise Medicine in 2018 selecting the first batch of trainees, which is aland mark in Sports Medicine education in Sri Lanka.

5. In addition to the MD program at PGIM, the graduates of Sports Medicine diploma have exhaled, taking different paths in obtaining post graduate qualifications internationally in the area of Sports M edicine and Rehabilitation. Dr Nalinda Andraweera consultant physician in Rehabilitation Medicine MSc, MD (Australia), Dr. Chathuranga Ranasinghe, PhD in Sports and Exercise Medicine (Australia), Prof. Aranjan Karunanakaye, MScin Sports M edicine(UK) and few morein current training.

\section{Role of Sports M edicine in $\mathrm{N}$ ational Health Sector as seen by BOSSM}

Given that the principleof patients carein Sports M edicineis to "treat as players and not as patients", the need for differently trained doctors and paramedical staff who understand the requirements of 
sports medicine is paramount, to servethe public in health sector hospitals.

BOSSM recognizes that sports medicine is not only postgraduate teaching, but that it encompasses providing services of Sports M edicineto athletes and to the general public of the entire country through Government Sector hospitals.

BOSSM recognized that sports medicineincludes “Doping in sports, miscellaneous medical conditions, cardio-pulmonary resuscitation in emergencies, health clubs and fitness facilities, use and misuse of equipment, basics of cardiac rehabilitation, preparticipation examination, causes and mechanism of sports injuries, sportspecific injuries, rehabilitation and therapeutic exercises, details of effects and uses of therapeutic exercises, mobilization and strengthening techniques and neuromuscular training, which go beyond the concept of curative medicine to highlight the importance of preventive and rehabilitativemedicine.

The BOSSM firstly projected the required cadre positions based on establishment of sports medicine units in hospitals to the Ministry of Health and also theSports Medicinecadrepositions of medical officer (MO)/ senior house officer (SHO) and consultants (MD). These cadre positions were endorsed by the Ministry of Health along with the approval of establishment of Sports M edicine units in hospitals. This enabled to formulate a plan to establish Sports Medicine units in Government Hospitals that progressed to the implementation stage.

The BOSSM also recognizes the multi stakeholder involvement which is needed for the development of the discipline; working cl osely with, Ministries of Health, Sports, Education and Higher Education, A cademia, National Olympic Committee of Sri Lanka, anti-doping agencies, sporting bodies and all relevant stakeholders.

Sports M edicine plays a part both in healthy and ill people, and has an influence on exercise, training and sports. Equally, it plays as important role on emphasizing the effect of regular exercise as a preventable causativefactor in NCDs and as one of the principal factors in preventing, coronary artery and cerebrovascular diseases. Sports Medicinethat explains that 'Exerciseis M edicine' and that exercise has an equally important rolein NCD prevention.

Sports Medicineservices by qualified doctors, is accepted as an important aspect of medical or health careservices globally. ThePGIM trained specialist in Sports Medicine would be able to use his or her training, experienceand theinfrastructurefacilities available in a hospital to deliver aspects of Sports Medicine, which will servethenational health care. 